\title{
Lung Cancer pT3 TNM Finding v6
}

National Cancer Institute

\section{Source}

National Cancer Institute. Lung CancerpT3 TNM Finding v6. NCI Thesaurus. Code C60970.

Lung cancer directly invading the chest wall (including superior sulcus tumors),

diaphragm, mediastinal pleura or parietal pericardium, or a tumor of any size extending into the main bronchus less than $2 \mathrm{~cm}$ distal to the carina but without involvement of the carina, or a tumor of any size with atelectasis or obstructive pneumonitis involving the entire lung. (from AJCC 6th Ed.) 